International Journal of Psychological Research and Reviews
(ISSN:2639-6041)

\title{
Adolescent Pornography: A Narrative Review
}

\section{Tiffany Field}

University of Miami/Miller School of Medicine, Fielding Graduate University

\begin{abstract}
This narrative review is based on a literature search on PsycINFO and PubMed that involved entering the terms adolescent Tiffany Field on the prevalence, effects and risk factors for pornography. Most versity

of the studies have been conducted in other countries where the prevalence of adolescent pornography has ranged from $8 \%$ $22 \%$ for habitual use. The effects of pornography have included legal problems, permissive attitudes and unrealistic expectations regarding sex as well as problematic behaviors including victimization and assault. The predictor or risk variables have included male gender, family dysfunction and sensation-seeking. Like other literature on adolescent problems, this research is limited by primarily deriving from self-report and parent report and by the absence of longitudinal data that might inform whether the data being reported are effects of or risk factors for adolescent pornography and the need for prevention/intervention research.
\end{abstract} ${ }^{*}$ Correspondence to Author: pornography. Following exclusion criteria, 31 papers could be University of Miami/Miller School of classified as adolescent pornography studies including research Medicine, Fielding Graduate Uni-

How to cite this article:

Tiffany Field. Adolescent Pornography: A Narrative Review. International Journal of Psychological Research and Reviews, 2020, 3:36

Keywords: adolescent pornography

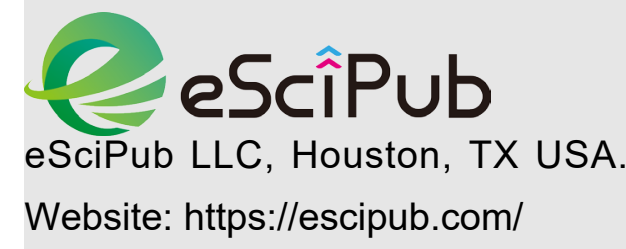


This narrative review is based on a literature search on PsycINFO and PubMed that involved entering the terms adolescent pornography. The inclusion criteria were peer reviewed empirical studies. Exclusion criteria were case studies and non-English papers. Following these criteria, 31 papers could be classified as adolescent pornography studies including research on the prevalence, effects and risk factors for pornography. Most of the studies have been conducted in other countries where the prevalence of adolescent pornography has ranged from $8-22 \%$ for habitual use. The effects of pornography have included legal problems, permissive attitudes and unrealistic expectations regarding sex as well as problematic behaviors including victimization and assault. The predictor or risk variables have included male gender, family dysfunction and sensation seeking. Like other literature on adolescent problems, this research is limited by primarily deriving from self-report and parent report and by the absence of longitudinal data that might inform whether the data being reported are effects of or risk factors for adolescent pornography. Virtually no prevention/intervention research appears in this literature. This narrative review is accordingly divided into sections on the prevalence of adolescent pornography, the effects of and the risk factors for adolescent pornography as well as a section on the methodological limitations of this literature

\section{Prevalence of Adolescent Habitual Pornography}

The prevalence of habitual (daily) pornography among adolescents has varied by country. In Sweden, for example, $10 \%$ of a sample of 453 adolescent boys had used pornography every day as compared to average users (63\%) and non-frequent users (27\%) (Mattebo, Tyden, Haggstrom-Nordin, Nilsson \& Larsson, 2013). The frequent versus the average users and nonfrequent users had more sexual activity such as one night stands and sex with friends for more than 10 times. The frequent users also reported spending more than 10 straight hours at a computer several times per week, truancy at least once a week and obesity, tobacco and alcohol use. Further, they suggested that they had more relationship problems with peers. At least one third of the frequent users said that they watched pornography more than they wanted. Surprisingly, the groups did not differ on physical and psychological health.

In a study from Italy on 1163 adolescents, 70\% of them admitted to using pornographic material and of these, $8 \%$ reported accessing pornographic websites on a daily basis (Pizzol, Bertoldo \& Foresta, 2016). Of the boys who accessed these sites, pornography was viewed as being "always stimulating" (59\%), as being habitual (22\%), as reducing sexual interest towards partners (10\%) and as a kind of addiction (9\%). In a sample of Malaysian adolescents, the prevalence of pornography was $27 \%$ while $9 \%$ engaged in pre-sexual activities (Azmawati, Dalila, Idris \& Hod, 2017). The predictive factors that were associated with pornography included being male, truancy, bullying, hanging out, staying out late and family conflict. In a large sample of Dutch adolescents, as many as $88 \%$ of the males and $45 \%$ of the females had consumed "sexually explicit materials" in the past 12 months (Hald, Kuyper, Adam \& de Wit, 2013).

\section{Effects of Adolescent Pornography}

One of the most serious effects of adolescent pornography is the potential legal consequences. Other effects include psychosomatic symptoms, negative attitudes and behaviors. Negative attitudes included depiction of males as dominant, negative body and sexual selfperceptions, permissive attitudes toward sex by males, unrealistic expectations regarding sex, and reduced sexual satisfaction. And, the negative behaviors include sexting, victimization and sexual assault. These of course could also be considered risks or predictors of adolescent pornography inasmuch as several of the studies were cross-sectional and not suggestive of causality.

\section{Legal Consequences}

IJPRR:https://escipub.com/international-journal-of-psychological-research-and-reviews/ 
The viewing and transferring of sexually explicit material by adolescents can be considered child pornography with serious legal consequences (Lorang, McNiel \& Binder, 2016). It may be prosecuted under state or federal child pornography laws (Holoyda, Landess, Sorrentino \& Friedman, 2018). As such, this could be considered one of the most severe effects as well as a major risk factor. The pornography laws reputedly disregard the consent and the age of the adolescent. Because of suicides and related tragedies, many jurisdictions are attempting to treat these offenses by adolescents as less serious (Cornwell, 2013). Several states have enacted legislation that differentiates adolescent pornography from that by adults (Lorang et al., 2016). This has happened in part because of the reputed difference in motivation for exchanging explicit sexual material by adolescents (Primack, 2017). However, the legal outcomes have continued to range from felony charges to no charges, and the rates have varied between $4 \%$ and $25 \%$ in the U.S. depending on the age of the adolescents and the content of the messages (Lorang et al., 2016).

\section{Negative Attitudes}

Several negative attitudes have been noted in the literature on the effects of adolescent pornography. These included viewing the male as dominant and the female as subordinate, developing negative perceptions about the body and sexual activity, permissive attitudes towards sexual behavior especially among males and unrealistic expectations towards sexual experience.

In a qualitative study, adolescents were interviewed in focus groups about pornography (Mattebo, Larsson, Tyden, Olsson \& HaggstromNordin, 2012). In this study, the male role was viewed as dominant and the female role as subordinate. Feelings of ambivalence were expressed towards pornography including anxiety and fear. Paradoxically, the adolescents also viewed pornography as a source of inspiration, and they felt pressured by the sexually explicit material.

In a longitudinal study on $11327^{\text {th }}$ to $10^{\text {th }}$ grade Dutch adolescents, greater levels of sex-related online behaviors predicted less physical selfesteem and less satisfaction with sexual experience (Doornwaard, Bickham, Rich, Vanwesenbeeck, van den Eijnden \& ter Bogt, 2014). Greater engagement in sex-related online behavior was predicted by private Internet access and less parental monitoring. In a later publication by the same group on the same longitudinal sample, sexually explicit Internet material increased across the 18-month period and that increase coincided with increases in permissive attitudes towards sex and experience with sexual behavior (Doornwaard, Bickham, Rich, ter Bogt \& van den Eijnden, 2015). In still a third paper by the same researchers, focus group sessions were conducted and themes of the sessions were coded (Doornwaard, den Boer, Vanwesenbeeck, van Nijnatten, Ter Bogt, \& van den Eijnden, 2017). A range of negative effects and risks emerged from these discussions including pornography creating unrealistic expectations about sexual activity and sexual attractiveness

In another longitudinal study but on Croatian adolescents, no pathways were noted from pornography to sexual permissiveness (Martyniuk \& Stulhofer, 2018). Although there was significant pornography use, low levels of permissiveness were reported. The authors implied that these results are unique to their "traditional highly religious society".

\section{Negative behaviors}

The negative behaviors that have been implicated as effects of pornography include continuing pornography, sexting, sexual behavior, sexual dissatisfaction, victimization and assault. Once again, these data have often derived from regressions conducted on crosssectional data in which variables have been arbitrarily assigned as predictors or outcomes and therefore causality cannot be determined. 
In a longitudinal study from Sweden on 53 randomly selected senior high school classes, higher pornography consumption at baseline, being a girl, living with separated parents and attending a vocational high school program contributed to $69 \%$ of the variance in continued pornography consumption at a two-year followup (Mattebo, Tyden, Haggstrom-Nordin, Nilsson \& Larsson, 2018). In addition, a paradoxical finding was that less pornography at baseline and being a girl were related to depression symptoms at follow-up. These results are tempered by the high attrition rates ( $53 \%$ of boys and $40 \%$ of girls).

In a study from Belgium, pornography consumption was measured in a sample of 329 adolescents with a mean age of 17 years (Van Ouytsel, Ponnet \& Walrave, 2014). The results of the study suggested that sexting behaviors were significantly associated with pornography after controlling for age, gender and Internet use. In a study from Denmark, the authors claim that the association that has often been reported between distributing sexually explicit materials and sexual behaviors has limited sexual behaviors to sexually transmitted infections and sexual aggression rather than a broad range of sexual behaviors (Hald et al., 2013). In this online cross-sectional survey of 4600 adolescents, as many as $88 \%$ of the males and $45 \%$ of the females had consumed sexually explicit material during the past year. Although a variety of sexual behaviors were associated with sexually explicit material consumption, pornography only accounted for up to $4 \%$ of the variance, suggesting that many other variables were missing from this equation.

In a narrative review of the literature on longitudinal associations between sexually explicit material and adolescent's attitudes and behaviors, a total of 20 papers from nine different research groups were reviewed (Koletic, 2017). The results showed that sexually explicit material was associated with sexual attitudes and sexual behavior. But in addition, other variables were associated with sexually explicit material including self-esteem and sexual satisfaction as well as behavioral, cognitive and emotional well-being. The authors noted that there were insufficient methodologically rigorous longitudinal studies to warrant a systematic review and meta-analysis.

In a study on 3349 Malaysian adolescents, an anonymous questionnaire was distributed (Marret, \& Choo, 2018). Of that sample, 30\% met off-line with an online acquaintance. Verbal, physical or sexual assaults were reported by as many as $6 \%$ of these adolescents. In the data analysis, the risk variables for victimization were pornography, male gender, online access at an Internet café, and the absence of parental monitoring. Another study also showed that online sexual experience including pornography predicted subsequent victimization (Maas, Bray \& Noll, 2019). In this study from the U.S. on 296 female adolescents, the researchers explored the probability of pornography at time one predicting problematic behavior at time two. Experiencing online sexually explicit material at time one was predictive of the number of physically violent romantic partners and the current occurrence of sexual assault at time two as well as HIV risk.

In contrast to the above studies on negative behaviors resulting from pornography, at least two studies suggested no specific effects of pornography. In a longitudinal study on 2286 adolescents from schools in Estonia, Hungary, Italy, Lithuania, Spain, Sweden and the United Kingdom, there were no effects of pornography use on outcome variables (Hokby, Hadlaczky, Westerlund, Wasserman, Balazs, Germanvicius et al., 2016). The only significant associations were sleep loss related to Internet use and withdrawal (negative mood) when the Internet could not be accessed. In another study, adolescents were asked "whether asking questions about pornography made them use it?" (Koletic, Cohen, Stulhofer \& Kohut, 2019). Although the authors expected to see the question-behavior effect, they found no evidence that asking adolescents about 
pornography increased their subsequent use of pornography.

Risk Factors/Predictors of Adolescent Pornography

Several risk factors/predictors of adolescent pornography have been identified in this literature and typically these have been explored in multivariate studies. They could be categorized as demographic variables including age and gender, family dysfunction, peer pressure, negative self-regulation problems, interest in sexual activities and religious influences.

Table 1. Prevalence of adolescent pornography and first authors.

\begin{tabular}{ll}
\hline$\underline{\text { Prevalence }}$ & First authors \\
\hline Sweden- 10\% & Mattebo (2013) \\
Italy- 8\% & Pizzol \\
Malaysia- 27\% & Azmawati \\
\hline
\end{tabular}

Table 2. Effects of adolescent pornography and first authors.

Effects $\quad$ First authors

Legal consequences

Psychosomatic symptoms

Negative attitudes

Anxiety and fear

Less satisfaction with sex

Permissive attitudes re: sex

Unrealistic expectations re: sex

Negative behaviors

Sexting behaviors

Less sexual satisfaction

Verbal, physical sexual assaults

Victimization, HIV risk
Lorang, Comwell, Primack, Holoyla

Mattebo (2018)

Mattebo (2018)

Doornward (2014)

Doornward (2015)

Doornward (2017)

Van Ouystel

Koletic

Marret

Maas 
Table 3. Risk factors/ predictors of adolescent pornography and first authors.

Risk factors

Demographic Variables

Later adolescence

Shek, Peter

Male gender

Family dysfunction

Mothers not monitoring boys but prohibiting girls

Gesser-Edelsburg

Limited self-regulation

Greater susceptibility to peer pressure

Efrati

External locus of control

Greater loneliness

Greater sex-related online activity

Less psychological well-being

Doornwaard (2016)

Excessive sexual interests

$\underline{\text { Interest in sexual activities }}$

Greater sexual interest, realism regarding material, permissiveness

Greater sexual desire, alcohol and tobacco consumption

$\underline{\text { Religious influences }}$

Increased use at a greater rate

Decreased age-based increases
First authors
Doorwaard (2015)

Kastboom

Kohut

Rasmussen

\section{Demographic Variables}

Age, gender and family dysfunction have been significant risk factors. In a longitudinal study on 3291 adolescents living in Hong Kong, consumption of online pornography was greater than traditional pornography and there was an increase in the consumption of sexually explicit material across the high school years (Shek \& $\mathrm{Ma}, 2016)$. Additional variables were male gender, family dysfunction and negative youth development. In the same longitudinal database, the same authors reported that boys consumed pornographic material more often than girls and they showed that family dysfunction and negative youth development were associated with the use of pornography (Ma \& Shek, 2013). In a qualitative study on Arab adolescents and their mothers, in-depth interviews revealed that mothers did not monitor pornography and sexual activity of their boys but prohibited that behavior by their girls (Gesser-Edelsburg \& Abed Elhadi Arabia, 2018). Although the boys reported routine viewing of pornography, the girls denied engaging in pornography but at the same time suggested that their female friends viewed pornography.

In a review of 20 years of research on adolescents and pornography (1995-2015), the 
prevalence rates were highly variable but those adolescents who used pornography were more frequently male, older adolescents and came from dysfunctional families (Peter \& Valkenburg, 2016). In addition, the use of pornography was associated with more permissive sexual attitudes, sexual behavior and sexual aggression. Sensation-seeking was another significant variable suggesting that selfregulation problems.

\section{Limited Self-regulation}

Limited capacity for self-regulation and increased susceptibility to peer pressure have been implicated as risk factors for the use of pornography by adolescents (American College of Obstetricians' and Gynecologists' Committee on Adolescent Healthcare, 2016). The view of this committee was that exposure to pornography increases the risk of sexually transmitted infections and pregnancy. Although external locus of control has been a significant factor in at least one study (Efrati \& Gola, 2018), the absence of peer pressure variables in this research is surprising as it appears in the literature on comorbidities of pornography including Internet addiction (Field, 2018), cyberbullying (Field, 2019), and sexting (Field, 2019). In a study on profiles of compulsive sexual behavior among adolescents, individuals who engaged in pornography had external locus of control along with greater loneliness and more sex-related online activity (Efrati et al, 2018). Surprisingly, loneliness has not appeared as a risk factor in other studies on adolescent pornography, although it has been a risk factor in adolescent internet addiction studies (Field. 2018). And, also surprisingly, a recent study on psychological well-being and adolescents' pornography use suggested that there were no negative effects of pornography on psychological well- being, at least in this longitudinal database on Croatian high school students (Stulhofer Tafro \& Kohut, 2019). However, lower psychological well-being and excessive sexual interests have been significant predictors in a study on Dutch boys (Doornwaard, van den Eijden, Baams, Vanwesenbeeck \& ter Bogt, 2016).

\section{Interest in Sexual Activities}

Adolescents' interest in sexual activities has been a risk factor in several studies. In the longitudinal study on Dutch boys, higher levels of depressive feelings and excessive sexual interests predicted increased compulsive use of sexually explicit Internet materials six months later (Doornwaard et al., 2016). In another publication by the same authors, the predictor variables for sexually explicit Internet material included stronger sexual interest, a greater degree of "perceived realism" regarding the content of that material and more permissive sexual attitudes in boys (Doornwaard, van den Eijden, Overbeek \& ter Bogt, 2015). But those patterns did not appear in the data on girls. In a cross-sectional survey involving 3380 Swedish adolescents, only $25 \%$ had not had sex by the age of 18 years (Kastboom, Sydsjo, Bladh, Priebe \& Svedin, 2016). That sex-free group engaged in lower pornography consumption and also had lower sexual desire and lower alcohol and tobacco consumption. The absence of literature on substance use as a risk factor for pornography in adolescents is surprising given its frequent association with other Internetrelated activities including Internet addiction (Field, 2018) and sexting (Field, 2019), activities that would be presumed to be comorbid with online pornography.

\section{Religious Influences}

Religiosity has had mixed effects on pornography in adolescents. For example, in a study on two independent samples of male Croatian adolescents, religious users started with lower initial levels of pornography but increased their use at a greater rate over time (Kohut \& Stulhofer, 2018). In contrast, in a study on Canadian adolescents, religion had a moderating influence (Rasmussen \& Bierman, 2016). Pornography occurred less in those who had higher levels of religious attendance and religious attendance weakened the age-based increases in pornography in both girls and boys. 


\section{Limitations of the Literature}

Limitations of this literature relate to both the content and the methodology. Regarding the content, which affects the methodology, there are many missing pieces starting with the definition of pornography. The lines between sexting and pornography have not been defined. The adolescents could be reporting sexting but not pornography because of the legal implications of child pornography. The relationship between sexting and pornography and whether sexting leads to the more serious problem of child pornography has not been studied. Under-reporting of pornography even in anonymous surveys has been cited for girls. In at least one study, the girls denied pornography while at the same time they reported that their girlfriends engaged in pornography (GesserEdelsburg et al., 2018). And while the mothers in that study reported pornography for their sons, they denied that activity for their daughters. Further, parents of adolescent girls may not sign informed consents for their daughters to participate in pornography surveys which could also relate to the lower prevalence for pornography in adolescent girls versus boys.

The etiology of adolescent pornography is unclear since there have not been any potential underlying mechanism studies. Parental pornography may be a factor, although it has not been studied. Dysfunctional families have been a risk factor but not specifically parental pornography. Peer pressure has appeared as a predictor variable in a couple studies but has not been the focus of research. And, negative peer relationships have not been assessed in this research although they have been risk factors for other social media problems including cyberbullying (Field, 2019) and sexting (Field, 2019). Fear of missing out (FOMO) is a peerrelated factor that has been implicated in smartphone addiction studies (Field, 2020) but not in adolescent pornography research. Truancy was a common factor for prevalence of adolescent pornography mostly in other countries which may derive from social anxiety, loneliness and dysfunctional peer relations as well as providing private time for pornographic activity. Inadequate school performance may also be a risk factor for truancy that, in turn, contributes to adolescent pornography.

It is surprising that research on these comorbid social problems like peer pressure, FOMO and peer relationships has not appeared in this literature. It is also surprising that psychological problems that would be expected to be comorbid with adolescent pornography have rarely been studied including loneliness, depression, social anxiety and negative sexual identity. Further, the comorbidity of behavior problems which would be expected as they are also social media problems is missing from this literature. Comorbidity with Internet addiction, sexting, cyberbullying and even gaming would be expected to be researched alongside adolescent pornography.

Several methodological problems relate to the absence of research on the important missing variables just mentioned. The prevalence data have derived from studies in European countries possibly because the legal consequences for adolescent pornography in those countries may be less than in the US. The literature has been almost exclusively adolescent self-report. In other adolescent problem research adolescent self-report has been inconsistent with parental report, for example in cell phone addiction studies (Field, 2020). Parental report may have occurred less often in this literature because of the apparent lack of monitoring by parents and even when monitoring denying their adolescents involvement, again possibly because of the potential legal implications. Monitoring and observation studies are needed to profile the triggers of adolescent pornography and related comorbid activities.

Many of the studies have focused on single variables as if they are pet variables of great interest to the researchers. Multivariate studies are needed to identify profiles of adolescents at risk for pornography. In addition, while several social media problem studies have featured 
physiological variables, for example, heart rate variability and fMRIs to document activation and connectivity correlates, the adolescent pornography literature is lacking those data, again probably because of the legal risks of identifying adolescents at risk. Most of the studies have been cross-sectional and have arbitrarily assigned variables to predictor and outcome measures in regression analyses. However, causality cannot be determined except in longitudinal studies. Inasmuch as most of the studies are based on survey research, longitudinal follow-ups are methodologically difficult and often have high attrition rates.

Literally no intervention studies have appeared in the literature on adolescent pornography. Adolescents would be unlikely to volunteer for these studies because of the risk of being identified legally and their parents are not likely to sign informed consents in part because they are denying their adolescents' engagement in these activities and in part because they are protecting them from legal problems. This is a significant problem not only for reducing pornography but also for the associated problems including the attitudes of permissiveness and unrealistic expectations for sexual activity and the victimization and assault behaviors. And, the emotional well-being behaviors that are rarely mentioned in this literature including sleep problems, social anxiety, loneliness and depression would also benefit from interventions targeting pornography and adolescents.

\section{Summary}

This narrative review is based on a literature search on PsycINFO and PubMed that involved entering the terms adolescent pornography. Following exclusion criteria, 31 papers could be classified as adolescent pornography studies including research on the prevalence, effects and risk factors for pornography. Most of the studies have been conducted in other countries where the prevalence of adolescent pornography has ranged from $8-22 \%$ for habitual use. The effects of pornography have included legal problems, permissive attitudes and unrealistic expectations regarding sex as well as problematic behaviors including victimization and assault. The predictor or risk variables have included male gender, family dysfunction and sensation-seeking. Like other literature on adolescent problems, this research is limited by primarily deriving from self-report and by the absence of longitudinal data that might inform whether the data being reported are effects of or risk factors for adolescent pornography and the need for prevention/intervention research. Nonetheless, this literature has highlighted the significance of the adolescent pornography problem and need for further research.

\section{References}

1. American College of Obstetricians and Gynecologists' Committee on Adolescent Health Care., Committee opinion no 653 summary: Concerns regarding social media and health issues in adolescents and young adults. Obstetrics and Gynecology, 2016 Feb;127(2):414. 10.1097/AOG.0000000000001306.

2. Azmawati, M.N., Dalila, R., Idris, I.B. \& Hod, R. (2017). Bullying and truancy: Predictors to sexual practices among school-going adolescents in Malaysia- A cross-sectional study. The Medical Journal of Malaysia, 72, 298-305.

3. Cornwell, J.K. (2013). Sexting: $21^{\text {st }}$-Century statutory rape. SMU Law Review, 66, 111-156.

4. Doornwaard, S.M., Bickham, D.S., Rich, M., ter Bogt, T.F. \& van den Eijnden, R.J. (2015). Adolescents' use of sexually explicit internet material and their sexual attitudes and behavior: Parallel development and directional effects. Developmental Psychology, 51, 1476-1488.

5. Doornwaard, S.M., Bickham, D.S., Rich, M., Vanwesenbeeck, I., van den Eijnden, R.J. \& ter Bogt, T.F. (2014). Sex-related online behaviors and adolescents' body and sexual selfperceptions. Pediatrics, 134, 1103-1110.

6. Doornwaard, S.M., van den Eijden, R.J., Baams, L., Vanwesenbeeck, I. \& ter Bogt, T.F. (2016). Lower psychological well-being and excessive sexual interest predict symptoms of compulsive use of sexually explicit internet material among adolescent boys. Journal of Youth and Adolescence, 45, 73-84.

7. Doornwaard, S.M., van den Eijden, R.J., Overbeek, G. \& ter Bogt, T.F. (2015). Differential developmental profiles of adolescents using 
sexually explicit internet material. Journal of Sex Research, 52, 269-281.

8. Doorwaard, S.M., den Boer, F., Vanwesenbeeck, I., van Nijnatten, C.H.C.J., Ter Bogt, T.F.M. \& van den Eijnden, R.J.J.M. (2017). Dutch adolescents' motives, perceptions, and reflections toward sexrelated internet use: Results of a web-based focus-group study. Journal of Sex Research, 54, 1038-1050.

9. Efrati, Y. \& Gola, M. (2018). Understanding and predicting profiles of compulsive sexual behavior among adolescents. Journal of Behavioral Addiction, 7, 1004-1014.

10. Field, T. (2018). Internet addiction in adolescents: A review. Journal of Addictions and Therapies, 1, 1-11.

11. Field, T. (2018). Cyberbullying: A narrative review. Journal of Addiction Therapy and Research, 2, 10-27.

12. Field, T. (2019). Adolescent sexting: A narrative review. International Journal of Psychological Research and Reviews.

13. Field, T. (2020). Facebooking by adolescents: A narrative review.

14. Gesser-Edelsburg, A. \& Abed Elhadi Arabia, M. (2018). Discourse on exposure to pornography content online between Arab adolescents and parents: Qualitative study on its impact on sexual education and behavior. Journal of Medical Internet Research, 2018 Oct 9;20(10):e11667. Doi: $10.2196 / 11667$.

15. Hald, G.M., Kuyper, L., Adam, P.C. \& de Wit, J.B. (2013). Does viewing explain doing? Assessing the association between sexually explicit materials and sexual behaviors in a large sample of Dutch adolescents and young adults. Journal of Sex Medicine, 10, 2986-2995.

16. Hokby, S., Hadlaczky, G., Westerlund, J., Wasserman, D., Balazs, J., Germanvicius, A. et al. (2016). Are mental health effects of internet use attributable to the web-based content or perceived consequences of usage? A longitudinal study of European adolescents. JMIR Mental Health, 2016 Jul 13;3(3):e31. Doi:10.2196/mental.5925.

17. Holoyda, B., Landess, J., Sorrentino, R. \& Friedman, S.H. (2018). Trouble at teens' fingertips:Youth sexting and the law. Behavioral Sciences \& the Law, 36, 170-181.

18. Kastbom, A.A., Sydsjo, G., Bladh, M., Priebe, G. \& Svedin, C.G. (2016). Differences in sexual behavior, health, and history of child abuse among school students who had and had not engaged in sexual activity by the age of 18 years:
A cross-sectional study. Adolescent Health, Medicine and Therapeutics, 7, 1-11.

19. Kohut, T. \& Stulhofer, A. (2018). The role of religiosity in adolescents' compulsive pornography use: A longitudinal assessment. Journal of Sex and Marital Therapies, 44, 759755.

20. Koletic, G. (2017). Longitudinal associations between the use of sexually explicit material and adolescent's attitudes and behaviors: A narrative review of studies. Journal of Adolescence, 57, 117-133.

21. Koletic, G., Cohen, N., Stulhofer, A. \& Kohut, T. (2019). Does asking adolescents about pornography make them use it? A test of the question-behavior effect. Journal of Sex Research, 56, 137-141.

22. Landripet, I., Busko, V. \& Stulhofer, A. (2019). Testing the content progression thesis: A longitudinal assessment of pornography use and preference for coercive and violent content among male adolescents. Social Science Research, 81:32-41.

23. Lorang, M.R., McNiel, D.E. \& Binder, R.L. (2016). Minors and sexting: Legal implications. Journal of American Psychiatry and Law, 44, 73-81.

24. Ma, C.M. \& Shek, D.T. (2013). Consumption of pornographic materials in early adolescents in Hong Kong. Journal of Pediatric and Adolescent Gynecology, 26, 18-25.

25. Maas, M.K., Bray, B.C. \& Noll, J.G. (2019). Online sexual experiences predict subsequent sexual health and victimization outcomes among female adolescents: A latent class analysis. Journal of Youth and Adolescence, 48, 837-849.

26. Marret, M.J. \& Choo, W.Y. (2018). Victimization after meeting with online acquaintances: A crosssectional survey of adolescents in Malaysia. Journal of Interpersonal Violence, 33, 2352-2378.

27. Martyniuk, U. \& Stulhofer, A. (2018). A longitudinal exploration of the relationship between pornography use and sexual permissiveness in female and male adolescents. Journal of Adolescence, 69, 80-87.

28. Mattebo, M., Larsson, M., Tyden, T., Olsson, T. \& Haggstrom-Nordin, E. (2012). Hercules and Barbie? Reflections on the influence of pornography and its spread in the media and society groups of adolescents in Sweden. European Journal of Contraceptive and Reproductive Health Care, 17, 40-49.

29. Mattebo, M., Tyden, T., Haggstrom-Nordin, E., Nilsson, K.W. \& Larsson, M. (2013). Pornography consumption, sexual experiences, lifestyles, and self-rated health among male adolescents in 
Sweden. Journal of Development and Behavior in Pediatrics, 34, 460-468.

30. Mattebo, M., Tyden, T., Haggstrom-Nordin, E., Nilsson, K.W. \& Larsson, M. (2018). Pornography consumption and psychosomatic and depressive symptoms among Swedish adolescents: A longitudinal study. Upsala Journal of Medical Sciences, 123, 237-246.

31. Peter, J. \& Valkenburg, P.M. (2016). Adolescents and pornography: A review of 20 years of research. Journal of Sex Research, 53, 509-531.

32. Pizzol, D., Bertoldo, A. \& Foresta, C. (2016). Adolescents and web porn: A new era of sexuality. International Journal of Adolescent Medical Health, 28, 169-73.

33. Primack, A.J. (2017). Youth sexting and the First Amendment: Rhetoric and child pornography

34. doctrine in the age of translation. New Media \& Society, 20, 2917-2933.

35. Rasmussen, K. \& Bierman, A. (2016). How does religious attendance shape trajectories of pornography use across adolescence? Journal of Adolescence, 49, 191-203.

36. Shek, D.T. \& Ma, C.M. (2016). A six-year longitudinal study of consumption of pornographic materials in Hong Kong. Journal of Pediatric and Adolescent Gynecology, 29, 12-21.

37. Stulhofer, A., Tafro, A. \& Kohut, T. (2019). The dynamics of adolescents' pornography use and psychological well-being: A six-wave latent growth and latent class modeling approach. European Child and Adolescent Psychiatry, 2019 Mar 27. Doi: 10.1007/s00787-019-01318-4. [Epub ahead of print].

38. Van Ouystel, J., Ponnet, K. \& Walrave, M. (2014). The associations between adolescents' consumption of pornography and music videos and their sexting behavior. Cyberpsychology, Behaviors and Social Networking, 17,772-778. 